\title{
Impact of Air Transport on the Noise Level in the City of Burgas
}

\author{
Stela Todorova ${ }^{1 *}$, and Kaloyan Haralampiev ${ }^{2}$ \\ ${ }^{1}$ Management and Marketing Department, University of Agriculture, Bulgaria \\ ${ }^{2}$ Department of Sociology, Sofia University “St. Kliment Ohridski”, Bulgaria
}

\begin{abstract}
Aviation, as every type of transport, is responsible for a number of negative external effects to the environment. The main goal of this study is to reveal the relation between the noise level in the urban areas near to the Burgas airport and the air traffic. Our main research tasks are: to make a literature review of the problem; to gather data for the noise levels; to gather data for the air traffic; to choose relevant statistical methods and models for the revealing of the relation between the noise level and air traffic; to draw conclusions and to make recommendations about the noise pollution in the vicinity of Burgas Airport. The data are on monthly basis and cover the period from January 2015 to December 2017 , i.e. 36 months. In our regression model we use three traffic indicators as independent variables: aircraft movements; passengers and freight. In the established regression model we introduce 'the time' as an additional factor, which provides concrete practical advantages. Our results show that two independent variables (aircraft movements and freight) affect the Twenty-four hours average equivalent level of noise due to flights. Aircraft movements are the most important factor and we expect their increasing in the future. This will lead to increased noise levels.
\end{abstract}

\section{Aims and background}

Aviation, as every type of transport, is responsible for a number of negative external effects that are not neutral to the environment. Aviation is responsible for a small extent of a global environmental pollution, estimated approximately at $2-3 \%$. These pollutions are generated mainly in the area of airports [1].

Aviation noise reduction is a problem that occurred in the middle of the last century in connection with the intensive operation of jet airplanes. It is still up to date and is an important part of the issues of ensuring human safety for the environment. In recent decades, the development and production of prospective civilian and military aircraft are betting environmental requirements for noise reduction, which are regulated by the ICAO [2].

Civilian and military aircrafts produce significant amounts of sound, the majority of which is produced from either a turbofan or a turbojet engine [3, 4]. Such engines generate relatively high amounts of vibration and turbulence. The main source of sound emanating from a jet aircraft results from the waves produced by the expanding gases of the jet exhaust stream [3]. One of the most familiar and possibly most severe forms of aircraft noise is the sonic boom. This term describes the propagation of positive and negative air pressure generated by the aircraft traveling at speeds from one to five times the speed of sound in air. Rotary-wing aircraft, or helicopters, are also a source of severe low-frequency sound and vibration [4].
Environmental noise is an unwanted or harmful external sound caused by human activity, incl. the noise emitted by vehicles from road, rail, water and air transport, from industrial installations and equipment as well as from local sources of noise. Noise pollution is generally defined as the exposure of people or animals to levels of sound that are annoying, stressful, or damaging to the ears. Humans are exposed to noise constantly, from barely audible levels to potentially painful and damaging levels.

A large number of studies emphasize negative health effects of air traffic on populations living in the vicinity of airports [5]. They point out that long-term exposure to noise caused by aircrafts disturbs everyday life and leads to increased irritability and impaired quality of life $[6,7]$, reduction in working capacity, disturbance in the learning process, impairment of memory abilities [8, 9], and serious difficulties in communication, especially when using a foreign language [10]. Literature reports cardiovascular disturbances and the risk of mental disorders and other diseases [11] has been reported in places with high levels of noise intensity, such as military airports [12].

Some studies are mainly focused on the damage associated with exposure to aircraft noise on wildlife populations. For example, military activities have triggered redness in bald eagles (Haliaeetus leucocephalus) [13]. Studies also establish the number of collisions between aircraft and birds [14]. Studies of the effects of noise exposure in animals have shown that "fear" is a common response [15]. During a fear response, the animal tries to escape the noise by running or flying away.

Corresponding author: stelatodorova_au@ @otmail.com, This research was supported by Bulgarian National Science Fund grand 
In their study for Burgas airport Turnovska, Staykova, Petkov [5] reported that, the diseases in populations living close to airports which, according to literature, might have an etiology in aircraft noise, are of paramount interest. Psychic disorders, neuroses diseases of the nervous system and sense organs have been reported to be in positive dependence with the stress-producing influence of aircraft noise and the degree of involvement correlates with the intensity and the duration of exposure.

The main goal of this paper is to reveal the relation between the noise level in the urban areas near to the Burgas airport and the air traffic. Our main research tasks are:

- To make a literature review of the problem;

- To gather data for the noise levels;

- To gather data for the air traffic;

- To choose relevant statistical methods and models for the revealing of the relation between the noise level and air traffic;

- To draw conclusions and to make recommendations about the noise pollution.

\section{Experimental}

Our data sources for the noise level are Quarterly Reports with Results of Continuous Measurements of the Noise Giving a Notion for the Acoustic State of Areas Located near Burgas Airport [16]. The data are on monthly basis and cover the period from January 2015 to December 2017 , i.e. 36 months.

Therefore, we gather data for the air transport for these 36 months. The data source is Statistical Information about the International Airports in the Republic of Bulgaria [17].

The noise indicators are:

- Twenty-four hours average equivalent level of cumulative noise:

- Twenty-four hours average equivalent level of noise due to flights;

- Twenty-four hours average equivalent level of background noise.

The noise is registered in four location points - one east of the airport and three southwest. They are denoted as MP01, MP02, MP03 and MP04. Larger numbers show a larger distance from the airport. However, there are full time series only for MP01, MP03 and MP04. In addition, there are missing values and we interpolated these missing values by exponential smoothing. For the other location point there are more missing values and because of that we excluded this location points from our data set. As a result, we have data for three location points that are presented on Figure 1

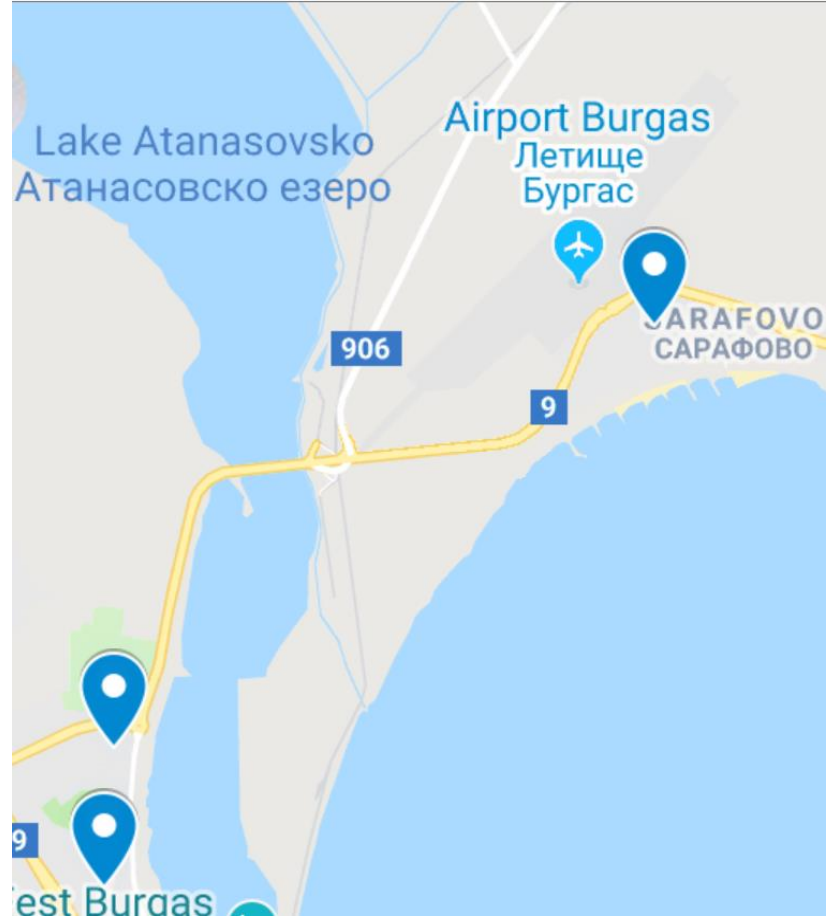

Fig. 1. Noise registration location points

In our analysis we use only the first two noise indicators as dependent variables. As dependent variable we take the average mean of all three location points each month. Thus we measure the noise that affects approximately 200000 people. $^{\text {a }}$ The air traffic indicators are:

- Aircraft movements (Thousands)

- Passengers (Thousands)

- Freight (Tons)

We use all these three traffic indicators as independent variables.

Our data set consists of time series. However "the correlation between such series could prove deceivably strong if the trends in these series are identical by chance" [18]. In such cases we need to get rid of the so-called autocorrelation, i.e. the influence of the former state of the researched phenomenon on its present state. There are lots of ways for doing so, but the most elegant and easy way is to introduce time in the model. Introducing time in the model is based on a corollary of the Frisch-Waugh theorem, which states that the "correlation of the residuals around trend lines is equal to the establishment of a multifactor regression model for the expression of the dependence between the absolute values of the $\mathrm{Y}$ and $\mathrm{X}$ series with the additional factor of time t" [18].

As long as the regression model is built upon time series, we introduce 'the time' as an additional factor in our model, which provides concrete practical advantages: 1) simplifying the calculation procedures; and 2) providing the opportunity to account for all other factors that we do not control for [18].

\section{Results and discussion}

\footnotetext{
a According to the National Census conducted in 2011
} 


\subsection{Noise pollution}

The noise levels in the urban areas near to the Burgas airport are presented on Figure 2:

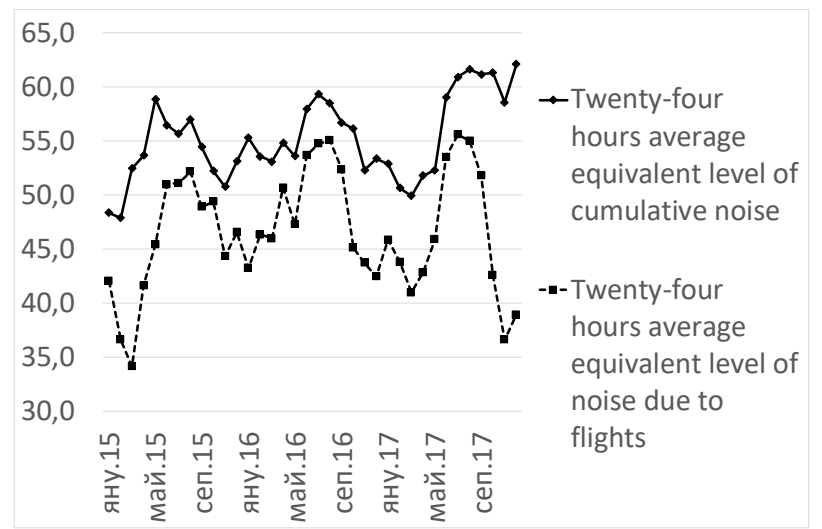

Fig.2. Noise levels in the urban areas near to the Burgas airport

According to the National Report on the State and Protection of the Environment in Bulgaria, chapter Noise Pollution [19], noise level 50-80 dB makes it difficult to hear speech and noise levels of about 50-60 dB have a harmful effect on the nervous system of the people and disturb their work and rest. Unfortunately, Figure 2 shows that the cumulative noise level in the urban areas near the Burgas Airport is above $50 \mathrm{~dB}$. This makes it important to study the factors that affect the noise level in order to find solutions for its reduction.

\subsection{Regression model with dependent variable Twenty-four hours average equivalent level of cumulative noise}

Collinearity diagnostics showed that the independent variable Passengers (Thousands) depends on all others independent variables and must be excluded. The new model is adequate $(\mathrm{F}=13.66, \mathrm{p}=0.000)$ and its multiple $\mathrm{R}$ Square is 0.562 , i.e. $56.2 \%$ of the variance of the Twenty-four hours average equivalent level of cumulative noise are explained by all independent variables together. The coefficients of the new model are presented in Table 1 .

Table 1. Coefficients of the regression model with dependent variable Twenty-four hours average equivalent level of cumulative noise

\begin{tabular}{|l|c|c|c|}
\hline $\begin{array}{c}\text { Independent } \\
\text { variables }\end{array}$ & $\begin{array}{c}\text { Unstandardized } \\
\text { coefficients }\end{array}$ & $\begin{array}{c}\text { Significance } \\
\text { level }\end{array}$ & $\begin{array}{c}\text { Partial } \\
\text { correlations }\end{array}$ \\
\hline $\begin{array}{l}\text { Aircraft } \\
\text { movements } \\
\text { (Thousands) }\end{array}$ & 0.999 & 0.000 & 0.611 \\
\hline $\begin{array}{l}\text { Freight } \\
\text { (Tons) }\end{array}$ & 0.001 & 0.375 & 0.157 \\
\hline Time & 0.157 & 0.001 & 0.542 \\
\hline
\end{tabular}

Increasing the Aircraft movements by 1000 results in an increase in the Twenty-four hours average equivalent level of cumulative noise by $1.00 \mathrm{~dB}$, provided that the other factors in the model do not change. The Twenty- four hours average equivalent level of cumulative noise increases by $0.16 \mathrm{~dB}$ monthly, provided that the other factors in the model do not change. Freight does not affect statistically significant the Twenty-four hours average equivalent level of cumulative noise.

\subsection{Regression model with dependent variable Twenty-four hours average equivalent level of noise due to flights}

Collinearity diagnostics showed that the independent variable Passengers (Thousands) depends on all others independent variables and must be excluded. The new model is adequate $(\mathrm{F}=29.51, \mathrm{p}=0.000)$ and its multiple $\mathrm{R}$ Square is 0.735 , i.e. $73.5 \%$ of the variance of the Twenty-four hours average equivalent level of noise due to flights are explained by all independent variables together. The coefficients of the new model are presented in Table 2.

Table 2. Coefficients of the regression model with dependent variable "Twenty-four hours average equivalent level of noise due to flights"

\begin{tabular}{|l|c|c|c|}
\hline $\begin{array}{c}\text { Independent } \\
\text { variables }\end{array}$ & $\begin{array}{c}\text { Unstandardized } \\
\text { coefficients }\end{array}$ & $\begin{array}{c}\text { Significance } \\
\text { level }\end{array}$ & $\begin{array}{c}\text { Partial } \\
\text { correlations }\end{array}$ \\
\hline $\begin{array}{l}\text { Aircraft } \\
\text { movements } \\
\text { (Thousands) }\end{array}$ & 2.191 & 0.000 & 0.828 \\
\hline $\begin{array}{l}\text { Freight } \\
\text { (Tons) }\end{array}$ & 0.002 & 0.040 & 0.354 \\
\hline Time & 0.003 & 0.944 & 0.012 \\
\hline
\end{tabular}

Increasing the Aircraft movements by 1000 results in an increase in the Twenty-four hours average equivalent level of noise due to flights by $2.19 \mathrm{~dB}$, provided that the other factors in the model do not change. Increasing the Freight by 1 Ton results in an increase in the Twenty-four hours average equivalent level of noise due to flights by $0.002 \mathrm{~dB}$, provided that the other factors in the model do not change. The time does not affect statistically significant the Twenty-four hours average equivalent level of noise due to flights.

\subsection{Mechanisms to reduce aircraft noise}

Two independent variables (Aircraft movements and Freight) affect the Twenty-four hours average equivalent level of noise due to flights. It is easy to explain since the noise during take-offs and landings is almost the same irrespective of the amount of cargo and mail carried by the airplanes. Rather it depends on the types of the aircrafts.

On the other hand, it is also easy to explain why the Freight appears as statistically significant factors together with Aircraft movements. That is because the transportation, loading and unloading of the freights produce additional noise.

Since the Aircraft movements are the most important factor and we expect their increasing in the future, this would lead also to the increasing of the noise levels. 
That's why other technical solutions for reducing noise levels should be sought.

Aviation noise is more irritating than noise from other sources for two reasons. The usual noises in the residential environment are relatively constant (ground transport, noise from household appliances, etc.), while aircraft noise consists of sporadic noise events with a certain rising and falling pattern. People do not perceive it as yet another component of the daily "background noise" and every fly-over is noticeable and irritating. Another characteristic that determines this impact of aircraft noise is its higher frequency and power to which the human ear is particularly sensitive [20].

The problem of reducing the level of aircraft noise is the main environmental issue to protect the environment from the impacts of aviation and is central to the activities of international environmental and aviation organizations. The reduction of noise from airports should be sought in two directions: 1) a good urban development solution that does not create the conditions for too close the city to the airport. At Burgas Airport this requirement is to a certain extent respected. 2) decisions regarding the design of the airplane, the engine and the path of its movement.

The solutions for reducing aircraft noise are:

1. Selecting new "noisy" engines, reducing night flights, investing in noise abatement technologies, fines, operating restrictions and quotas. At night, the quietest aircraft are allowed to land and flights are further limited by a point system known as a quota reporting system. For each landing and take-off, airplane noise level points accumulate, with cumulative points not exceeding a certain amount over a certain period of time. Many airports charge landing and take-off fees based on the results of aircraft noise certification [21].

2 . Reduce the resistivity of the aircraft by reducing the required traction. Improving the aerodynamic efficiency of the aircraft by reducing resistance or thrust, respectively, reduces the amount of fuel required and emissions [21].

\section{Conclusions}

Our study shows cumulative noise levels in urban areas near Burgas Airport are above $50 \mathrm{~dB}$ and the aircraft noise affects approximately 200000 people.

National legislation concerning aircraft noise is oriented towards the introduction of standards for aircraft noise, detecting and mapping the distribution of noise around airports, collection of data for aviation through closed (not publicly oriented) monitoring systems and distribution of non-operational information for the observed noise.

Consequently, operating aircrafts at Burgas Airport generate noise above the norm in the districts "Sarafovo", "Izgrev", "Slavejkov" and "Zornica". It is necessary to control the flight management in compliance with the meteorological conditions and the flushing of the adjacent territories of Burgas Airport on the basis of the data from the own monitoring system, located along the takeoff/landing route.
Noise caused by human activity, including aircraft noise, does not directly lead to pollution of the natural environment, but directly impacts the quality of life.

\section{References}

1. M. Jez, Ekologiczna problemy portu lotniczego. Prace Instytutu Lotnictwa Nr 4 (206), Wydawnictwa Naukowe Instytutu Lotnictwa, p. 59-71, (2010).

2. Directive 2002/30 / EC; NAREDBA №16 from 14.01.1999.

3. K. M. Manci, D. N. Gladwin, R. Villella, Effects of aircraft noise and sonic booms on domestic animals and wildlife: a literature synthesis. NERC 88/29, AFESC RE 88.14, (1988).

4. D. K. Delaney, T. G. Grubb, P. Beier, L. L. Pater, M. H. Reiser, Effects of helicopter noise on Mexican spotted owls. Journal of Wildlife Management 63, p. 60-75, (1999).

5. T. Turnovska, J. Staykova, T. Petkov, Health Assessment In Populations Exposed To Aircraft Noise. Arh Hig Rada Toksikol, 55, p. 5-10, (2004).

6. S. Fidell, L. Silvati, E. Haboly, Social survey of community response to a step change in aircraft noise exposure. J Acoust Soc Am, 111:200-9, (2002).

7. M. Haines, S. Stansfeld, S. Brentnall, J. Head, B. Berry, M. Jiggins, S. Hygge, The West London Schools Study: the effects of chronic aircraft noise exposure on child health. Psychol Med, 31:1385-96, (2001).

8. J. Hatfield, R. F. Job, A. J. Hede, N. L.Carter, P. Peploe, R. Taylor, S. Morrell, Human response to environmental noise: the role of perceived control. Int J Behav Med, 9:341-59, (2002).

9. S. Hygge, G. W. Evans, M. Bullinger, A prospective study of some effects of aircraft noise on cognitive performance in schoolchildren. Psychol Sci, 13:46974, (2002).

10. T. Shimizu, K. Makishima, M.Yoshida, H.Yamagishi, Effect of background noise on perception of English speech for Japanese listeners. Auris Nasus Larynx, 29:121-5, (2002).

11. M. Haines, S. Stansfeld, S. Brentnall, J. Head, B. Berry, M. Jiggins, S. Hygge, The West London Schools Study: the effects of chronic aircraft noise exposure on child health. Psychol Med, 31:1385-96, (2001)

12. T. Miyakita, T. Yoza, T. Matsui, A. Ito, K. Hiramatsu, Y. Osada, T. Yamamoto, An epidemiological study regarding the hearing acuity of residents in the area with high level of aircraft noise: results of hearing tests conducted in the vicinity of Kadena Air Base. Nippon Eiseigaku Zasshi, 56:577-87, (2001).

13. M. V. Stalmaster, J. L. Kaiser, Flushing responses of wintering bald eagles to military activity. Journal of Wildlife Management 61:1307-1313, (1999).

14. J. Burger, Jet aircraft noise and bird strikes: Why more birds are being hit. Article in Environmental 
Pollution Series A Ecological and Biological 30(2):143-152, (1983).

15. J. Bond, Rumsey, T. S. Menear, J. R. Colbert, L. I. Kern, D. Weinland, Effects of simulated sonic booms on eating patterns, feed intake and behavioral activity of ponies and beef cattle. International Livestock Symposium. Department of Agriculture, ARS, BARC-East, Beltsville, Maryland 20705. SP-0174, American Society of Agriculture Engineers, US, (1974).

16. Executive Environment Agency of Bulgaria, Quarterly Reports with Results of Continuous Measurements of the Noise Giving a Notion for the Acoustic State of Areas Located near Burgas Airport, http://eea.government.bg/bg/dokladi/threemonth/

17. Directorate General "Civil Aviation Administration" of Bulgaria, Statistical Information about the
International Airports in the Republic of Bulgaria, https://www.caa.bg/bg/category/292/statisticheskainformaciya

18. N. Velichkova, Statistical Methods for Studying and Forecasting the Development of Socio-economic Phenomena, Sofia (1981).

19. Executive Environment Agency of Bulgaria, National Report on the State and Protection of the Environment in Bulgaria, chapter Noise Pollution, http://eea.government.bg/bg/soer/2014/noise/index

20. A. Lazarova, Aviation noise, New Bulgarian University, Sofia, (2005)

21. K. Tochev, L. Tabanliev, A. Chozhgova, S. Asenov, Construction solutions of reducing aircraft noise. Mechanics Transport Communications 3, number 1, Sofia, http://www.mtc-aj.com, (2014) 